\title{
Process integration models for emerging challenges: Optimal allocation of antivirals under resource constraints
}

\section{Charlle Sy}

De La Salle University

\section{Kathleen Aviso}

De La Salle University

Christina Cayamanda

Animolabs Foundation

Anthony Chiu

De La Salle University

\section{Rochelle Lucas}

De La Salle University

Michael Promentilla

De La Salle University

\section{Luis Razon}

De La Salle University

Raymond Tan ( $\sim$ raymond.tan@dlsu.edu.ph )

De La Salle University

\section{John Frederick Tapia}

De La Salle University

Ador Torneo

De La Salle University

Aristotle Ubando

De La Salle University

\section{Derrick Yu}

De La Salle University

Keywords: Pharmaceutical shortage; Resource allocation; COVID-19; mathematical programming; disease outbreak; Sustainable Development Goal

Posted Date: April 23rd, 2020

DOI: https://doi.org/10.21203/rs.3.rs-24325/v1 
License: (c) (i) This work is licensed under a Creative Commons Attribution 4.0 International License. Read Full License 


\title{
Process integration for emerging challenges: Optimal allocation of antivirals under resource constraints
}

\author{
C. L. Sy ${ }^{1}$, K. B. Aviso ${ }^{1}$, C. D. Cayamanda ${ }^{2}$, A. S. F. Chiu ${ }^{1}$, R. I. G. Lucas ${ }^{3}$, M. A. B. Promentilla ${ }^{1}$, \\ L. F. Razon ${ }^{1}$, R. R. Tan ${ }^{1}$, J. F. D. Tapia ${ }^{1}$, A. R. Torneo ${ }^{4}$, A. T. Ubando ${ }^{1}$, D. E. C. $\mathrm{Yu}^{5}$
}

\begin{abstract}
The global scientific community has intensified efforts to develop, test, and commercialize pharmaceutical products to deal with the COVID-19 pandemic. Trials for both antivirals and vaccines are in progress; candidates include existing repurposed drugs that were originally developed for other ailments. Once these are shown to be effective, their production will need to be ramped up rapidly to keep pace with the growing demand as the pandemic progresses. It is highly likely that the drugs will be in short supply in the interim, which leaves policymakers and medical personnel with the difficult task of determining how to allocate them. Under such conditions, mathematical models can provide valuable decision support. In particular, useful models can be derived from process integration (PI) techniques that deal with tight resource constraints. In this paper, a linear programming (LP) model is developed to determine the optimal allocation of COVID-19 drugs that minimizes patient mortality, taking into account additional hospital capacity constraints. Two hypothetical case studies are solved to illustrate the computational capability of the model, which can generate an allocation plan with outcomes that are superior to simple ad hoc allocation.
\end{abstract}

Keywords: Pharmaceutical shortage; Resource allocation; COVID-19; mathematical programming; disease outbreak; Sustainable Development Goals

\footnotetext{
${ }^{1}$ Center for Engineering and Sustainable Development Research, De La Salle University

${ }^{2}$ AnimoLabs Foundation, Inc.

${ }^{3}$ Lasallian Institute for Development and Educational Research, De La Salle University

${ }^{4}$ Jesse M. Robredo Institute of Governance, De La Salle University

${ }^{5}$ Center for Natural Science and Environmental Research, De La Salle University
} 


\section{Introduction}

The COVID-19 pandemic has escalated dramatically in the span of just a few months into the worst health crisis of the $21^{\text {st }}$ Century (Bandyopadhyay, 2020). According to the World Health Organization (WHO, 2020), the disease has now infected more than 1.7 million people and killed about 100,000 victims worldwide. The United States, Spain, Italy, Germany, France, the United Kingdom, China, Iran, and Turkey, have been hit particularly hard with 50,000 or more cases each, with five countries having over 10,000 fatalities. Smaller countries, such as Taiwan, Singapore, and New Zealand, have thus far demonstrated relatively successful control measures. The situation in highly populated developing countries (e.g., India) and regions (e.g., Southeast Asia) is still unfolding and uncertain.

The pandemic has adverse implications on international progress towards most of the Sustainable Development Goals. Ferguson et al. (2020) reported simulations showing that the COVID-19 pandemic, left unchecked, can rapidly overwhelm the healthcare systems of even affluent countries like the United States and the United Kingdom. They also showed how aggressive suppression measures - i.e., lockdowns with stringent restrictions on the mobility of the public - can delay the progress of the pandemic to minimize the strain on healthcare capacity. Numerous countries responded by imposing lockdown measures with nonpharmaceutical interventions (NPIs) to "flatten the curve" and spread out COVID-19 cases over a longer period of time at a rate that can be handled by their healthcare systems (Ferguson et al., 2020). This approach is almost universally accepted as the best control measure in the absence of effective pharmaceutical interventions.

In addition to health issues, COVID-19 has links to different dimensions of sustainability. The virus is believed to have originated via cross-species transmission from either bats (Zhou et al., 2020) or pangolins (Zhang et al., 2020). Genetic analysis of the virus belies conspiracy theories about its synthetic origin (Xu, 2020), but suggests that it may have been spreading more extensively in humans in late 2019 than previously thought (Andersen et al., 2020). The emergence of this novel pathogen underscores the risks resulting from human encroachment on natural habitats (Cunningham et al., 2017). The origin of this virus and the response of governments has mixed implications for ecosystems.

On the one hand, the post-COVID-19-era may see more stringent regulations on the capture and consumption of wildlife (Yuan et al., 2020). On the other hand, ubiquitous lockdown measures have effectively put a stop to many conservation efforts (Corlett et al., 2020). The biosphere will also be affected by environmental impacts resulting from healthcare measures. For example, the sheer volume of hazardous medical waste from hospitals threatens to overwhelm waste treatment capacity, in exactly the 
same manner that the pandemic surge threatens to overwhelm healthcare systems (Klemeš et al., 2020). Air emissions from the cremation of the remains of COVID-19 victims will also escalate. Once effective drugs are found for the treatment of COVID-19, metabolites in human waste will become an issue (Celiz et al., 2009). Such trace pollutants are problematic because they are not destroyed by sewage treatment systems, but require novel processing technologies for proper waste management (Majumdar and Pal, 2020)

The suppression measures being implemented in most parts of the world, while necessary, also come with adverse socio-economic consequences. Reduced economic output creates upstream and downstream cascading effects that can cross national boundaries ( $\mathrm{Yu}$ and Aviso, 2020). These impacts are then felt by workers in different economic sectors as loss of income (Santos et al., 2013). The pandemic has also led to an increase in the level of output in other industries, such as those providing medical supplies, delivery services, and web-based communication platforms to facilitate remote work and education. Some of these responses may eventually persist in the post-COVID-19 world as permanent post-disaster structural changes in economic systems (Okuyama, 2014). It is likely that these changes will have mixed positive and negative environmental impacts. For example, more extensive use of work-from-home arrangements after the pandemic will reduce emissions of greenhouse gases and air pollutants generated from daily commuting.

In response to the pandemic, efforts to develop pharmaceutical interventions for COVID-19 have been intensified. The development of new vaccines and dedicated antivirals are currently in progress, but such products are unlikely to be available within 2020. Repurposing existing drugs offers the promise of a more timely solution. The World Health Organization (WHO) is currently running the SOLIDARITY trials to find therapeutic drugs for COVID-19. The candidate drugs in the trial (remdesivir, chloroquine/hydroxychloroquine, ritonavir/lopinavir, and ritonavir/lopinavir-interferon-beta) are already commercially available for the treatment of other diseases. They can, in principle, be administered sooner than other antivirals and vaccines, which will still need to pass regulatory hurdles (Kupferschmidt and Cohen, 2020). However, it has also been pointed out by Yu et al. (2020) that ramping up the production capacity of these drugs will be a serious engineering and business challenge for pharmaceutical supply chains. Potential roadblocks include bottlenecks in drug synthesis or the sourcing of specialty chemical precursors. There is also a clear risk of countries imposing barriers to the trade of critical products or raw materials. 
In the likely event of future shortages of COVID-19 drugs, mathematical models can be used to aid decision-makers in developing rational allocation policies that are superior to ad hoc or heuristic approaches. Such models can be used for the allocation of vaccines and antivirals (Medlock and Galvani, 2009; Koyuncu and Erol, 2010), and can provide a computational framework for developing policies that respond dynamically to demand surge and shifting conditions (Arora et al., 2010; Yaesoubi and Cohen, 2016). They can be used to provide a rigorous basis for government regulations to manage drug shortages (Musazzi et al., 2020).

The field of process integration (PI) offers a practical engineering toolbox for dealing with such problems. PI was developed initially as a systematic and holistic approach for designing sustainable, resourceefficient industrial systems (El-Halwagi, 2006). It uses computational techniques such as pinch analysis (Klemeš et al., 2018), mathematical programming (Klemeš and Kravanja, 2013), and process graphs (Friedler et al., 2019), to aid in the design or retrofit of industrial plants and planning of larger-scale systems such as industrial parks and supply chains. While the original purpose was to economize on the use of industrial inputs such as fuel and water, there has been notable diversification in the literature in recent years, demonstrating the use of core PI principles for the efficient use of resources in general (Klemeš et al., 2018; Friedler et al., 2019). Recent studies which applied PI priciples as a decision-support tool on a pandemic outbreak have been performed. Liu et al. (2019) developed a mixed-integer non-linear programming (MINPLP) model to determine when to open and close the new isolated wards while quantifying the capacity and the budget requirement for the H1N1 outbreak. Aviso et al. (2018) developed a fuzzy input-output optimization model for the allocation of medical personnel in a hospital due to an immediate pandemic outbreak, thus, providing a human resource strategy for medical staff. Sun et al. (2014) developed a multi-objective optimization model for patient and resource allocation in hospitals to minimize the distance travelled by the patient in an influenza outbreak. However, no studies have been found which considers supply and hospital constraints while determining the optimal drug allocation.

In this paper, we develop a linear programming (LP) model based on PI principles to determine the optimal allocation of future COVID-19 drugs considering constraints on their supply, as well as hospital capacity. The computational capabilities of the model are illustrated using two hypothetical case studies. In both examples, it is shown that the LP model can reduce patient mortality compared to ad hoc or heuristic allocation policies. The rest of the paper is organized as follows: Section 2 gives the formal problem statement that the LP addresses. Section 3 describes the model formulation. Section 4 shows a simple illustrative example meant for pedagogical purposes. Section 5 discusses a simulated scenario 
based on the projected near-future situation in the National Capital Region (NCR) of the Philippines. Finally, Section 6 gives the conclusions and discusses prospects for future work.

\section{Problem Statement}

The formal problem addressed by the model is as follows. Given the following user-specified inputs:

- A limited amount of antivirals that can be given to an infected population;

- $\quad m$ severity levels of infection each requiring a specific level of health care;

- $n$ population groups with known mortality rate of patients in each severity level when receiving or not receiving appropriate health care;

- $o$ regions where there are cases of infection;

- $\quad p$ types of hospital resources with known availability for each region;

- Efficacy of antivirals, as quantified by the average transfer rate of patients between severity levels upon receipt of treatment;

The model determined the optimal allocation of available antivirals and the corresponding minimum number of total deaths. The model is static and assumes a fixed set of patients and resources for a given planning time frame. In practice, it can be applied sequentially to a given cohort of patients using resource data available at that point in time. Input data can be subsequently updated as new data is acquired for replanning.

\section{Model formulation}

Sets

M Set of severity levels

$\mathrm{N} \quad$ Set of population age group

$\mathrm{O} \quad$ Set of regions

$\mathrm{P} \quad$ Set of available hospital resources

W Set of available antiviral types

Indices

i Index for severity level

j Index for population group

$\mathrm{k} \quad$ Index for region 
$\begin{array}{ll}\mathrm{r} & \text { Index for resource type } \\ \mathrm{V} & \text { Index for antiviral type }\end{array}$

$\mathrm{V} \quad$ Index for antiviral type

Parameters

$\alpha_{i} \quad$ Mortality rate of individuals in severity level $\mathrm{i}$ who did not get needed resource

$\beta_{i} \quad$ Mortality rate of individuals in severity level i who received proper resources

$C A P_{v} \quad$ Total number of antiviral type $v$ available

$A_{i, j, v} \quad$ Probability that group $\mathrm{j}$ will be in severity level i for antiviral given

$D_{i, r} \quad$ Amount of hospital resource $\mathrm{r}$ needed by individual in severity level $\mathrm{i}$

$S_{r, k} \quad$ Total available resource $\mathrm{r}$ in region $\mathrm{k}$

$\mathrm{X}_{\mathrm{j}, \mathrm{k}}^{\mathrm{T}} \quad$ Total number of infected symptomatic individuals in population group $\mathrm{j}$ in region $\mathrm{k}$

\section{Variables}
$u_{r, k}$
Actual number of resource type $\mathrm{r}$ used in region $\mathrm{k}$
$x_{j, k, v}^{A}$
Number of individuals in population group $\mathrm{j}$ in region $\mathrm{k}$ that were given antiviral v
$y_{i, k, v}^{A}$
Number of individuals in severity level $\mathrm{i}$ in region $\mathrm{k}$ who were given antiviral $\mathrm{V}$
$y_{i, k}^{N} \quad$ Number of individuals in severity level $\mathrm{i}$, in region $\mathrm{k}$ who did not receive required hospital resources
$y_{i, k}^{P} \quad$ Number of individuals in severity level $\mathrm{i}$ in region $\mathrm{k}$ who received required hospital resources
$y_{i, k}^{T} \quad$ Total number of individuals in severity level $\mathrm{i}$ in region $\mathrm{k}$
$z t_{k} \quad$ Total number of deaths in region $\mathrm{k}$ among those who had access to hospital resources
$z u_{k} \quad$ Total number of deaths in region $\mathrm{k}$ among those who did not have access to required hospital resources

The overall objective is to minimize the total number of deaths as given by Eq. 1 where $z t_{k}$ is the total number of deaths among those who had access to hospital resources in region $k$, and $z u_{k}$ is the total number of deaths among those who did not have access to hospital resources in region $k$.

$$
\min =\sum_{k=1}^{o} z t_{k}+z u_{k}
$$


The sum of infected symptomatic individuals are classified either as those not given antivirals and those given antiviral of a certain type $\left(x_{j, k, v}^{A}\right)$ for each population group $j$, region $k$, and antiviral type $v$, should equal the total number of infected symptomatic individuals for each population group and region $\left(X_{j, k}^{T}\right)$, as shown in Eq. 2. For an infected symptomatic individual in group $j$, the probability of getting an infection severity level $i$ will depend on whether the person was given an antiviral or not, and if yes, the type of antiviral $v$ given as defined in $\mathrm{A}_{\mathrm{i}, \mathrm{j}, \mathrm{v}}$. For each drug, these parameters constitute a transfer matrix that summarizes how treatment reclassifies patients to lower levels of severity. The total number of individuals from region $k$ who received antiviral type $v$ and experienced a severity level $i$ is obtained using Eq. 3, $y_{i, k, v}^{A}$ are the total number of individuals in severity level $i$ for region $k$ getting the treatment for antiviral $v$. The total number of infected individuals in each severity level for each region $\left(y_{i, k}^{T}\right)$ is then given by Eq. 4.

$$
\begin{array}{lr}
\sum_{v=1}^{W} x_{j, k, v}^{A}=\mathrm{X}_{\mathrm{j}, \mathrm{k}}^{\mathrm{T}} & \forall j, k \\
\sum_{j=1}^{n} \mathrm{~A}_{\mathrm{i}, \mathrm{j}, \mathrm{v}} x_{j, k, v}^{A}=y_{i, k, v}^{A} & \forall i, k, v \\
\sum_{v=1}^{W} y_{i, k, v}^{A}+y_{i, k}^{N}=y_{i, k}^{T} & \forall i, k
\end{array}
$$

The total number of individuals to be given the antiviral should not exceed the total number of antivirals available (Eq. 5).

$$
\sum_{j=1}^{n} \sum_{k=1}^{o} x_{j, k, v}^{A} \leq C A P_{v}
$$

Individuals who experience severity level $\mathrm{i}$ will require resource type $\mathrm{r}$ as indicated in $D_{i, r}$. Thus, region $\mathrm{k}$ can only provide for a limited number of infected individuals $\left(y_{i, k}^{P}\right)$ based on how much resource type $r$ is available in region $k\left(S_{r, k}\right)$, as shown in Eq. 6. All other infected individuals will not be able to access the required hospital resource $\left(y_{i, k}^{N}\right)$, as shown in Eq. 7. The actual number of resource type $r$ used in region $k$ $\left(u_{r, k}\right)$ is given by Eq. 8.

$$
\begin{array}{lc}
\sum_{i=1} y_{i, k}^{P} D_{i, r} \leq S_{r, k} & \forall r, k \\
y_{i, k}^{N}+y_{i, k}^{P}=y_{i, k}^{T} & \forall i, k
\end{array}
$$




$$
\sum_{i=} y_{i, k}^{P} D_{i, r}=u_{r, k}
$$

$\forall r, k$

The mortality rate will then depend on the severity level and whether the infected individual was given access to the required hospital resources as deemed necessary by the infection severity where $\alpha_{i}$ is the mortality rate for severity level $i$ for individuals with no access to resource and $\beta_{i}$ is the mortality rate for severity level $i$ for individuals with access to hospital resources. The total number of deaths in region $k$ for those who did not have access to the resources is given by Eq. 9, while the total number of deaths in region $k$ even with access to resources is shown in Eq. 10.

$$
\begin{aligned}
& \sum y_{i, k}^{N} \alpha_{i}=z t_{k} \\
& \sum y_{i, k}^{P} \beta_{i}=z t_{k}
\end{aligned}
$$

This formulation is an LP model that can be solved to global optimality with no computational difficulties. The next two sections apply the model to case studies implemented using the commercial optimization software LINGO 18.0, with solutions being determined in negligible CPU time using a laptop running on Windows 10 using the Intel ${ }^{\circledR}$ Core $^{\mathrm{TM}}$ i7-6500 CPU Processor at $2.50 \mathrm{GHz}$.. However, the model itself is generic and can be implemented in other software, including spreadsheet applications.

\section{Case Study 1}

In this section, a simple hypothetical example is given to illustrate the capabilities of the model. Given that there is one region with individuals infected by a certain epidemic and that the population can be grouped into mild, moderate, and critical cases, the total number of infected individuals for each population group is summarized in Table 1.

Three different treatments are possible: any given patient can be given Antiviral A, Antiviral B, or no antiviral at all. The probability of each risk group falling under infection severity levels based on the treatment received is given in Table 2. Note that these probabilities do not include the probability of being infected and being asymptomatic. Asymptomatic individuals will not require treatment. The effectiveness of the antivirals is quantified as by the rate of transfer of patients to lower severity levels. It can be seen that if an individual is administered with antiviral, the severity of the infection can be reduced. For 
example, without treatment, the patients remain in their original severity level (as signified by values of 1 in the diagonal of the transfer matrix and 0 in all other cells) and suffer the same mean levels of mortality. On the other hand, if Antiviral A is given to patients that initially require ICU confinement, the treatment is sufficiently effective to allow $80 \%$ of such patients to be reclassified to less resource-intensive regular hospital care. It should be noted that Antivirals A and B are hypothetical, and the efficacy figures shown here are purely for illustrative purposes; however, the model can use empirical parameters for future COVID-19 drugs once results of ongoing trials are published.

Table 1. Number of infected symptomatic individuals per region and population group $\left(X_{j, k}^{T}\right)$.

\begin{tabular}{|l|c|}
\hline \multicolumn{1}{|c|}{ Risk Level } & Number of Cases \\
\hline Low Risk & 800 \\
\hline Medium Risk & 150 \\
\hline High Risk & 50 \\
\hline Total & 1,000 \\
\hline
\end{tabular}


Table 2. Probability of infection severity due to the risk group and administration of antiviral

\begin{tabular}{|c|c|c|c|c|c|c|c|c|c|}
\hline & \multicolumn{3}{|c|}{$\begin{array}{c}\text { No Antiviral } \\
A_{i, j, 1}^{A}\end{array}$} & \multicolumn{3}{|c|}{$\begin{array}{c}\text { With Antiviral A } \\
A_{i, j, 2}^{A}\end{array}$} & \multicolumn{3}{|c|}{$\begin{array}{c}\text { With Antiviral B } \\
\qquad A_{i, j, 3}^{A}\end{array}$} \\
\hline $\begin{array}{c}\text { Group } \\
\text { Severity }\end{array}$ & Mild & Moderate & Critical & Mild & Moderate & Critical & Mild & Moderate & Critical \\
\hline Mild & 1 & 0 & 0 & 1 & 0.6 & 0 & 1 & 0.75 & 0 \\
\hline Moderate & 0 & 1 & 0 & 0 & 0.4 & 0.8 & 0 & 0.25 & 0.6 \\
\hline Critical & 0 & 0 & 1 & 0 & 0 & 0.2 & 0 & 0 & 0.4 \\
\hline
\end{tabular}


For each severity level, the resource needs are shown in Table 3. For this example, there are three types of resources : home care, regular hospital beds, and intensive care unit (ICU) beds. The total number of each resource type that is available in the region is given in Table 4. Individuals with mild severity will not require any hospital resources and are advised to stay home. The mortality of an individual is affected by whether they receive the necessary care depending on the severity of their illness. The mortality rates are summarized in Table 5. Furthermore, only 100 treatment courses of Antiviral A are available, while there are 200 treatment courses of Antiviral B. Each treatment course corresponds to daily dosage multiplied by the total duration of treatment, which is assumed to be the same for all patients.

Table 3. Resource requirement based on infection severity level $\left(D_{i, r}\right)$

\begin{tabular}{|l|c|c|c|}
\hline \multicolumn{1}{|c|}{ Severity } & Home Care & Hospital Bed & Intensive Care Unit \\
\hline Mild & 1 & 0 & 0 \\
\hline Moderate & 0 & 1 & 0 \\
\hline Critical & 0 & 0 & 1 \\
\hline
\end{tabular}

Table 4. Available resources

\begin{tabular}{|l|c|}
\hline Resource & Number of units \\
\hline Home Care & Unlimited \\
\hline Hospital Beds & 100 \\
\hline Intensive Care Units & 20 \\
\hline
\end{tabular}

Table 5. Mortality Rates by severity level and resource

\begin{tabular}{|l|c|c|}
\hline & No adequate care & With adequate Care \\
\hline Mild & 0.0 & 0.0 \\
\hline Moderate & 0.2 & 0.05 \\
\hline Critical & 1.0 & 0.50 \\
\hline
\end{tabular}

Different scenarios were considered for this example: Scenario 1.1: No antivirals are available; Scenario 1.2: Both antivirals are available and used interchangeably; Scenario 1.3: Allocation is optimized based on antiviral availability and known efficacy. 


\section{Scenario 1.1}

This scenario assumes the baseline case where no drugs are available to treat COVID-19. By solving Eq. 1 subject to the constraints outlined in Eqs. 2 to 10 with Eq. 5 indicating that there are no antivirals available $\left(C A P_{v}=0\right)$. Table 6 shows the number of individuals who receive proper care as well as those who do not are shown in Table 6. Since the total number of hospital beds available is only 100, 50 other patients suffering from medium severity are not given proper care. Similarly, only 20 critical patients get proper care, while 30 others do not. The patients not receiving adequate care suffer higher mortality rates, as shown in Table 5. As a result, a total of 55 deaths is experienced.

Table 6. Severity of infected individuals and their access to proper care for Scenario 1.1

\begin{tabular}{|l|c|c|c|}
\hline \multicolumn{1}{|c|}{ Severity } & With proper care & No proper care & Total \\
\hline Mild & 800 & 0 & 800 \\
\hline Moderate & 100 & 50 & 150 \\
\hline Critical & 20 & 30 & 50 \\
\hline
\end{tabular}

\section{Scenario 1.2}

For Scenario 1.2, an ad hoc allocation plan is assumed where the two antivirals are used interchangeably and prioritized for use by patients depending on severity level. The allocation of the antivirals is shown in Table 7. A total of 300 individuals are given antivirals, and as a result, the number of mild cases increases to 905 patients (13.1\% more than Scenario 1.1), while the moderate cases reduced to 88 patients $(41.3 \%$ lower than Scenario 1.1) and the critical cases to 17 patients (67\% lower than Scenario 1.1). In addition, all patients are able to get proper care within the limits of hospital resources. As a result, the number of deaths is reduced to 13 , which is a $76.4 \%$ reduction compared to Scenario 1.1 .

Table 7. Allocation of Antivirals for Scenario 1.2

\begin{tabular}{|l|c|c|c|c|}
\hline & Mild & Moderate & Critical & $\begin{array}{c}\text { Total antiviral } \\
\text { used }\end{array}$ \\
\hline No antiviral & 700 & 0 & 0 & NA \\
\hline Antiviral A & 33 & 50 & 17 & 100 \\
\hline Antiviral B & 67 & 100 & 53 & 200 \\
\hline Total infected & 800 & 150 & 50 & \\
\hline
\end{tabular}


Table 8. Severity of infected symptomatic individuals and their access to proper care for Scenario 1.2

\begin{tabular}{|l|c|c|c|}
\hline \multicolumn{1}{|c|}{ Severity } & With proper care & No proper care & Total \\
\hline Mild & 905 & 0 & 905 \\
\hline Moderate & 88 & 0 & 88 \\
\hline Critical & 17 & 0 & 17 \\
\hline
\end{tabular}

\section{Scenario 1.3}

For Scenario 1.3, the LP model is applied to determine the best drug allocation. These is enough Antiviral A for 100 patients and enough Antiviral B for 200 patients. Instead of using the two drugs interchangeably, the model assigns them to patients based on quantitative measures of their efficiacy for patients in different severity levels. The optimal result of antiviral allocation is shown in Table 9, while the number of cases with respect to severity is shown in Table 10. It can be seen that antiviral A is prioritized for the critical cases, while only antiviral B is only used for moderate cases. This allocation follows logically from performance parameters defined in Table 2, which shows that Antiviral A is the superior product for critical cases, while Antiviral B is superior for moderate cases. All surplus doses of the two drugs can then be given to patients with mild cases or, alternatively, held in reserve for future patients. The option not to administer medication to mild cases can also reduce downstream environmental impacts from trace pollutants from drug metabolization. As in Scenario 2, all individuals are able to receive proper care because the antivirals transfer patients to lower severity levels that fall within hospital resource limits. The total number of mild cases increases to $912(14.0 \%$ more than Scenario 1.1), the moderate case reduces to 78 patients $(48.0 \%$ less than Scenario 1.1$)$, and the critical cases also reduce to 10 patients $(80 \%$ less than Scenario 1.1). As a result, the total number of expected number deaths is further reduced to 9 individuals, which is an $83.6 \%$ reduction from Scenario 1.1. This figure is also $31 \%$ lower than the mortality level in Scenario 1.2.

Table 9. Allocation of Antivirals for Scenario 1.3

\begin{tabular}{|l|c|c|c|c|}
\hline & Mild & Moderate & Critical & Total antiviral \\
\hline No antiviral & 700 & 0 & 0 & NA \\
\hline Antiviral A & 50 & 0 & 50 & 50 \\
\hline Antiviral B & 50 & 150 & 0 & 150 \\
\hline Total infected symptomatic & 800 & 150 & 50 & \\
\hline
\end{tabular}


Table 10. Severity of infected symptomatic individuals and their access to proper care for Scenario 1.3

\begin{tabular}{|l|c|c|c|}
\hline \multicolumn{1}{|c|}{ Severity } & With proper care & No proper care & Total \\
\hline Mild & 912 & 0 & 912 \\
\hline Moderate & 78 & 0 & 78 \\
\hline Critical & 10 & 0 & 10 \\
\hline
\end{tabular}

A comparative summary of all three scenarios is shown in Table 11.

Table 11. Summary of Results

\begin{tabular}{|l|c|c|c|c|c|c|}
\hline \multirow{2}{*}{} & \multicolumn{2}{|c|}{ Scenario 1.1 } & \multicolumn{2}{c|}{ Scenario 1.2 } & \multicolumn{2}{c|}{ Scenario 1.3 } \\
\cline { 2 - 7 } & Antiviral A & Antiviral B & Antiviral A & Antiviral B & Antiviral A & Antiviral B \\
\hline Mild & 0 & 0 & 0 & 0 & 0 & 0 \\
\hline Moderate & 0 & 0 & 50 & 100 & 0 & 150 \\
\hline Critical & 0 & 0 & 17 & 33 & 50 & 0 \\
\hline No proper care & \multicolumn{2}{|c|}{80} & \multicolumn{2}{|c|}{0} & & 0 \\
\hline Proper care & \multicolumn{2}{|c|}{920} & \multicolumn{2}{|c|}{13000} & 1,000 \\
\hline Deaths & \multicolumn{2}{|c|}{55} & \multicolumn{2}{|c|}{9} \\
\hline
\end{tabular}

\section{Case Study 2}

Case study 2 builds upon the previous set of computational experiments by considering multiple regions in the National Capital Region (NCR). The densely populated NCR has a daytime population of 12.88 million and accounts for $12.8 \%$ of the 100.98 million total Philippine population, according to the Philippine Statistics Authority's 2015 census (PSA 2020a; b). It is the economic and political capital of the country and is currently the epicenter of COVID-19 infections. For this example, each of the 16 component cities and one municipality in the NCR are considered distinct regions. The subsequent set of computations uses the same set of parameters from the first case study, namely, the probability of infections (Table 2), resource requirement based on infection severity level (Table 3), and the mortality rates (Table 5). However, hospital resource availability was obtained from official statistics of the Philippine Department of Health (DoH, 2020). 


\section{Scenario 2.1: Availability of Antiviral Drugs}

This scenario considered how drug availability affects the number of deaths and the number of patients that would need access to hospital resources. This was implemented by varying the percentage from $10 \%$ to $100 \%$ of those patients that would be given either Antiviral A or B. Table 12 shows the number of deaths alongside how the Antiviral A and Antiviral B will be allocated to the infected population. It can be seen that the number of deaths decreases with the increasing availability of the two drugs. However, the number begins to plateau once drug availability reaches about $70 \%$, as shown in Figure 1 . This is primarily because of the large proportion of the infected population with mild cases of the disease. No added benefit is seen even if they take these drugs since they will remain under the same severity level. Hence, they need not be given any antiviral drugs, regardless of availability. It is assumed here that any surplus is stockpiled in reserve for a future surge of serious COVID-19 cases. Furthermore, as in Case Study 1, for critical cases, Antiviral A had a higher efficacy level than Antiviral B. Figures 2 and 3 show how Antiviral A is allocated to critical cases, while Antiviral B is allocated to moderate cases.

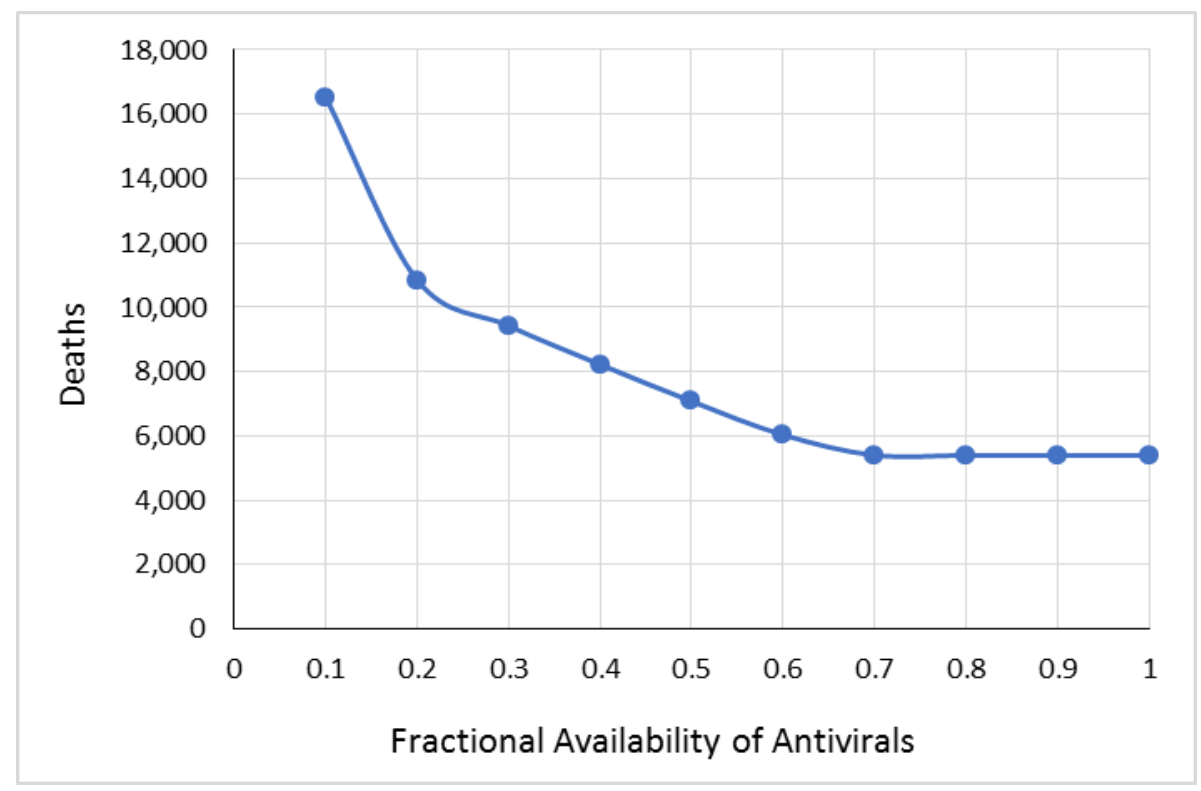

Figure 1. Variation in number of deaths relative to availability of antivirals 
Table 12. Optimal allocation of antivirals at different levels of supply availablity in Scenario 2.1

\begin{tabular}{|c|c|c|c|c|c|c|c|c|c|c|}
\hline \multirow{2}{*}{$\begin{array}{c}\text { Fractional } \\
\text { Availability }\end{array}$} & \multirow{2}{*}{ Deaths } & \multicolumn{4}{|c|}{ Mild } & \multicolumn{3}{|c|}{ Moderate } & \multicolumn{3}{c|}{ Critical } \\
\cline { 2 - 11 } & & Antiviral & $\begin{array}{c}\text { Antiviral } \\
\text { A }\end{array}$ & $\begin{array}{c}\text { Antiviral } \\
\text { B }\end{array}$ & $\begin{array}{c}\text { No } \\
\text { Antiviral }\end{array}$ & $\begin{array}{c}\text { Antiviral } \\
\text { A }\end{array}$ & $\begin{array}{c}\text { Antiviral } \\
\text { B }\end{array}$ & $\begin{array}{c}\text { No } \\
\text { Antiviral }\end{array}$ & $\begin{array}{c}\text { Antiviral } \\
\text { A }\end{array}$ & $\begin{array}{c}\text { Antiviral } \\
\text { B }\end{array}$ \\
\hline 0.1 & 16,527 & 32,577 & 0 & 0 & 45,087 & 0 & 0 & 8,708 & 9,597 & 0 \\
\hline 0.2 & 10,841 & 32,577 & 0 & 0 & 44,094 & 0 & 994 & 105 & 18,200 & 0 \\
\hline 0.3 & 9,421 & 32,577 & 0 & 0 & 34,602 & 0 & 10,486 & 0 & 18,305 & 0 \\
\hline 0.4 & 8,217 & 32,577 & 0 & 0 & 25,005 & 0 & 20,083 & 0 & 18,305 & 0 \\
\hline 0.5 & 7,076 & 32,577 & 0 & 0 & 15,408 & 0 & 29,680 & 0 & 18,305 & 0 \\
\hline 0.6 & 6,030 & 32,577 & 0 & 0 & 5,811 & 0 & 39,276 & 0 & 18,305 & 0 \\
\hline 0.7 & 5,400 & 32,577 & 0 & 0 & 42 & 0 & 45,046 & 0 & 18,305 & 0 \\
\hline 0.8 & 5,397 & 32,577 & 0 & 0 & 0 & 0 & 45,087 & 0 & 18,305 & 0 \\
\hline 0.9 & 5,397 & 32,577 & 0 & 0 & 0 & 0 & 45,087 & 0 & 18,305 & 0 \\
\hline 1 & 5,397 & 32,577 & 0 & 0 & 0 & 0 & 45,087 & 0 & 18,305 & 0 \\
\hline
\end{tabular}




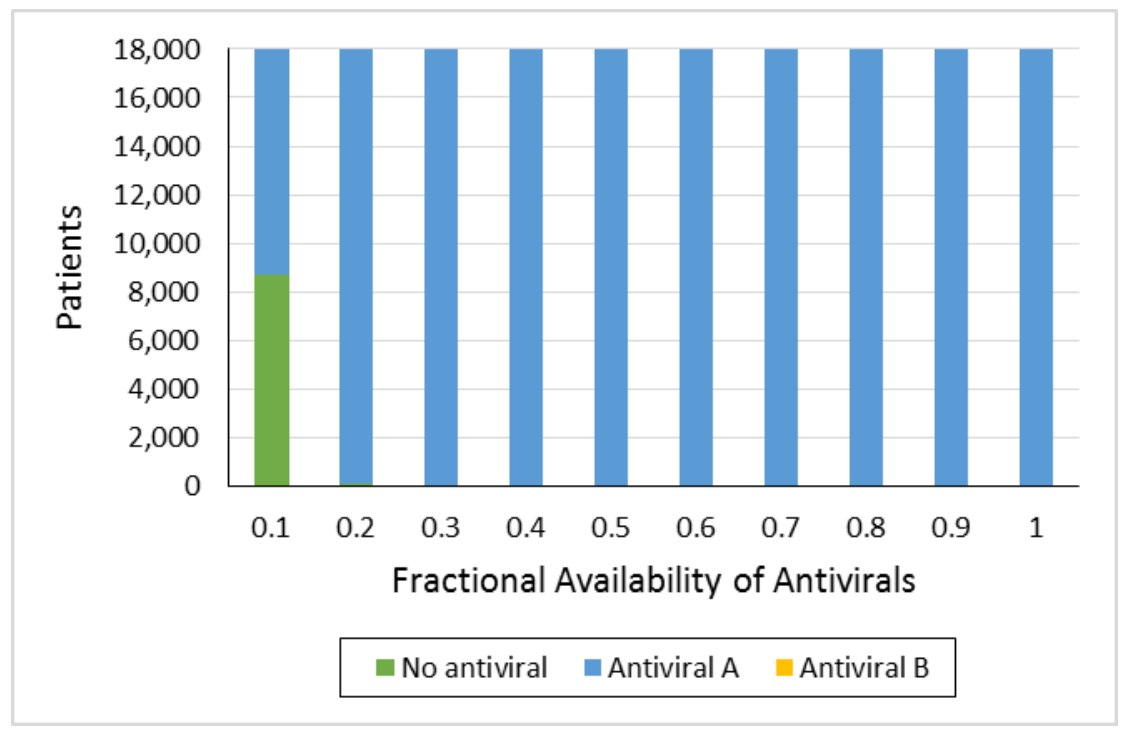

Figure 2. Allocation of antivirals to critical case patients.

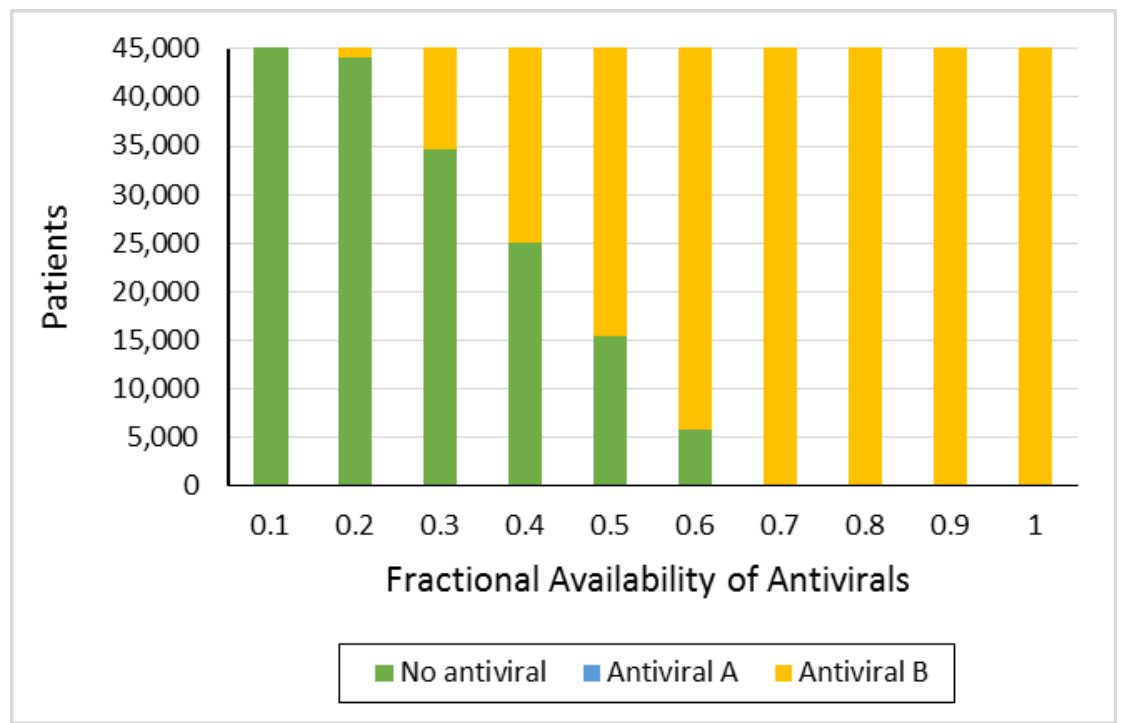

Figure 3. Allocation of antivirals to moderate case patients 
Figure 4 shows the proportion of patients who were able to gain access to the hospital resources they need that are appropriate to the severity of the infection. The results highlight how antiviral drugs decrease the burden on hospital resources, which may be needed for patients with other ailments. At 100\% antiviral availability, most of those infected will now be classified as mild cases that only need home care. Conversely, the need for hospital resources (regular ward and ICU beds) increases as drug availability decreases.

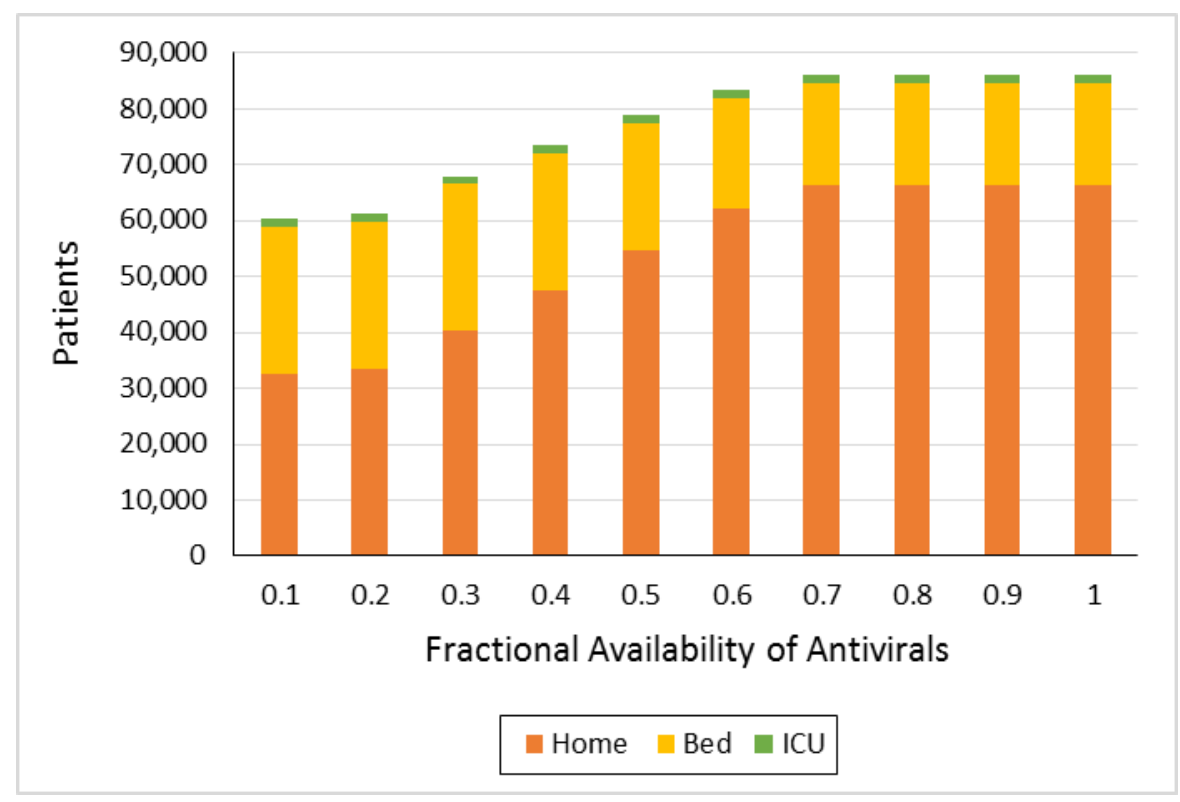

Figure 4. Distribution of patients at different levels of antiviral availability

\section{Scenario 2: Availability of hospital resources dedicated to COVID-19 patients}

The second scenario alternatively considers how the availability of hospital resources affects the number of deaths and access to the needed level of care with respect to the severity of the infection. In this scenario, it was assumed that drug availability is $100 \%$, i.e., all patients can get the antiviral drugs they need. As in the first scenario, the number of deaths decreases as more hospital resources get assigned specifically for COVID-19 patients. This result is due to patients falling under the different severity levels being able to get appropriate treatment. For instance, critical patients are able to access ICU beds, while those classified under moderate severity are assigned to isolation rooms inside the hospital. Another key observation here is that the number of deaths, even with only $10 \%$ availability, is still lower than the number recorded from Scenario 2.1. Again, this is because the antiviral drugs lower the severity levels of the infections - allowing some of the patients to become mild cases that will only require home care. 
Table 13. Optimal patient outcomes at different levels of hospital resource availability in Scenario 2.2

\begin{tabular}{|c|c|c|c|c|}
\hline $\begin{array}{c}\text { Fractional } \\
\text { Availability }\end{array}$ & Deaths & \multicolumn{3}{|c|}{ Access to hospital resources } \\
\hline 0.1 & 8,349 & Home & Bed & ICU \\
\hline 0.2 & 7,868 & 66,392 & 2,806 & 149 \\
\hline 0.3 & 7,397 & 66,392 & 5,534 & 291 \\
\hline 0.4 & 6,945 & 66,392 & 8,209 & 432 \\
\hline 0.5 & 6,538 & 66,392 & 10,751 & 572 \\
\hline 0.6 & 6,246 & 66,392 & 12,996 & 713 \\
\hline 0.7 & 5,991 & 66,392 & 14,473 & 854 \\
\hline 0.8 & 5,786 & 66,392 & 15,712 & 992 \\
\hline 0.9 & 5,581 & 66,392 & 16,633 & 1,126 \\
\hline 1 & 5,397 & 66,392 & 17,553 & 1,259 \\
\hline
\end{tabular}

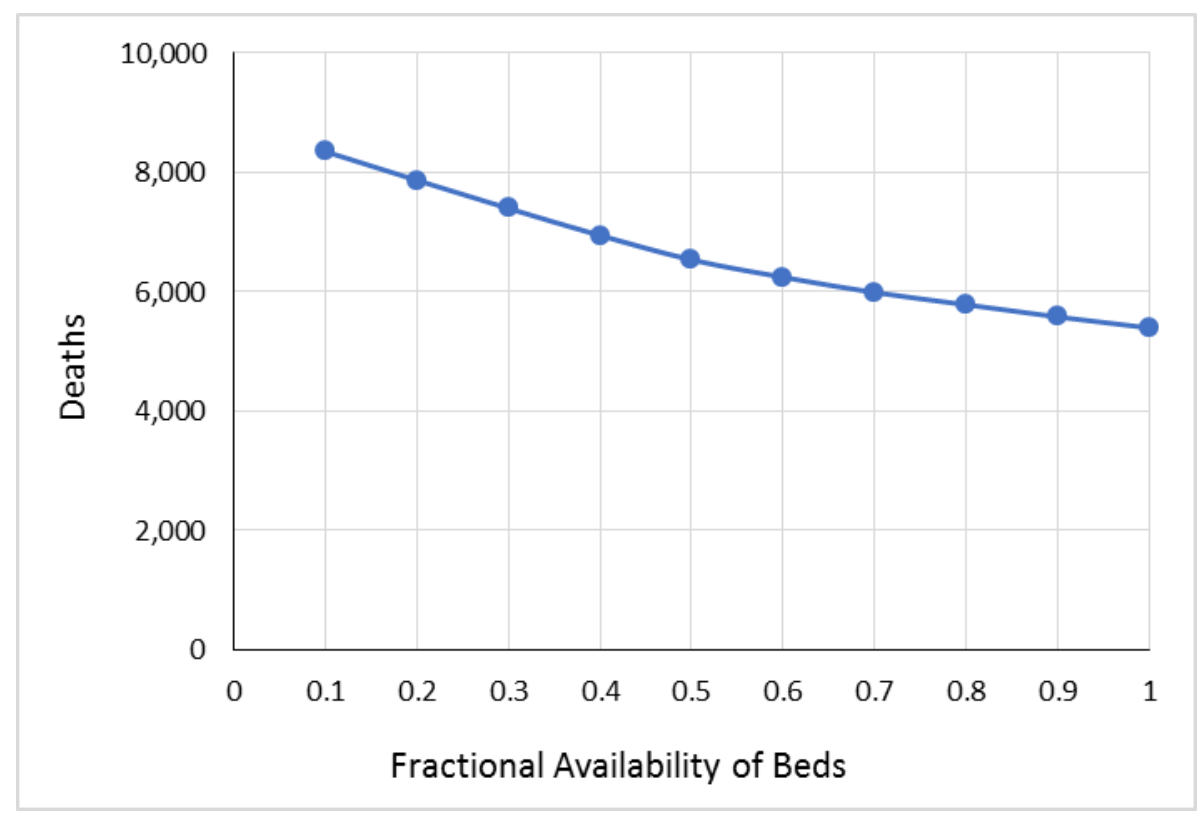

Figure 5. Variation in number of deaths relative to availability of hospital resources 


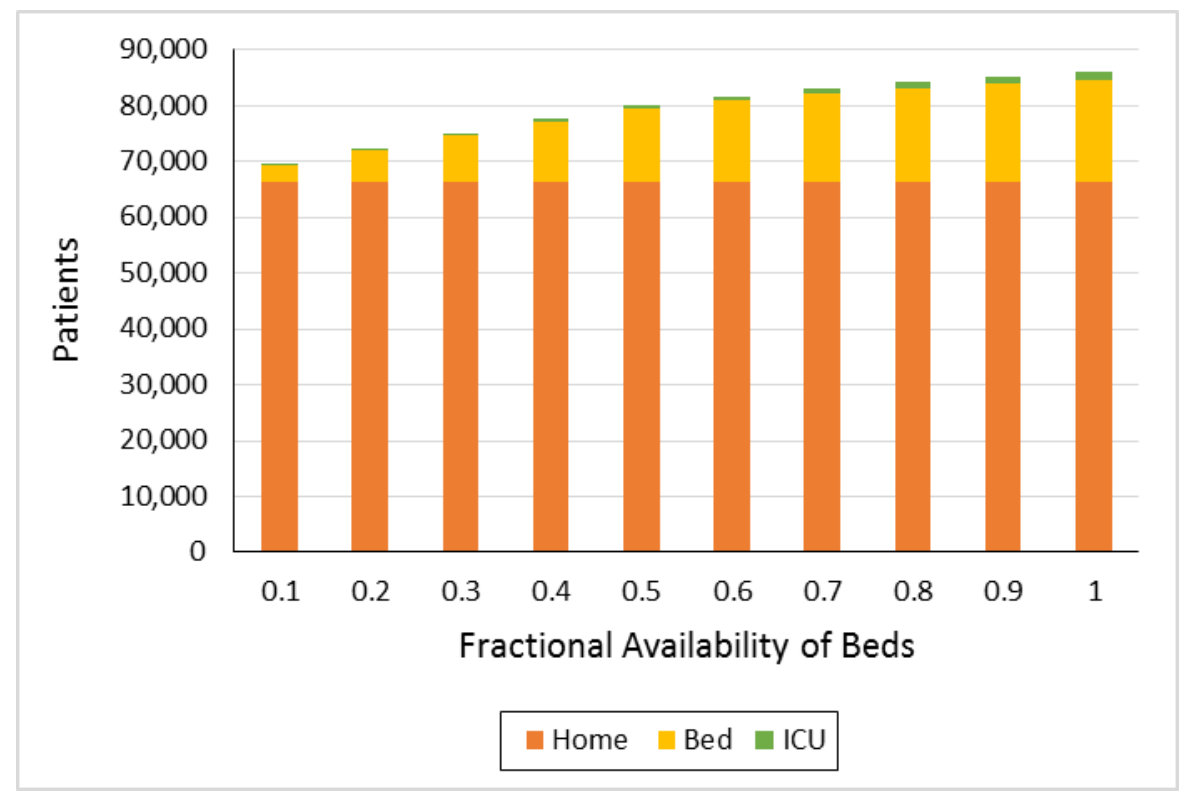

Figure 6. Distribution of patients at different levels of hospital resource availability

\section{Conclusions}

An LP model has been developed for optimizing the allocation of future COVID-19 drugs under conditions of a supply shortage. The model also accounts for hospital capacity due to limits on space, vital life support equipment, and medical personnel. Two case studies were solved to illustrate how the model can generate allocation policies that outperform ad hoc or heuristic policies using patient mortality as a metric. The model can provide strategic insights for government planners and health care administrators to complement the operational view of front-line medical personnel. The LP formulation is flexible, and it can be readily updated once published data on drug efficacy becomes available. As an LP, it can also be readily implemented and solved in commonly available software such as spreadsheets applications. This simple model can also serve as the core model for future extensions. In particular, robust, multi-period, and multi-objective variants should be prioritized for development to account for uncertainties, dynamics, and conflicting goals, respectively. 


\section{References}

Andersen, K. G., Rambaut, A., Lipkin, W. I., Holmes, E. C., Garry, R. F. 2020. The proximal origin of SARS-CoV-2. Nature Medicine, doi: 10.1038/s41591-020-0820-9.

Arora, H., Raghu, T. S., Vinze, A., 2010. Resource allocation for demand surge mitigation during disaster response. Decision Support Systems, 50, 304-315.

Aviso, K. B., Mayol, A. P., Promentilla, M. A. B., Santos, J. R., Tan, R. R., Ubando, A. T., Yu, K. D. S., 2018. Allocating human resources in organizations operating under crisis conditions: A fuzzy inputoutput optimization modeling framework. Resources, Conservation and Recycling, 128, 250-258.

Bandyopadhyay, S. 2020. Coronavirus Disease 2019 (COVID-19): we shall overcome. Clean Technologies and Environmental Policy, doi:10.1007/s10098-020-01843-w.

Celiz, M. D., Tso, J., Aga, D. S., 2009. Pharmaceutical metabolites in the environment: Analytical challenges and ecological risks. Environmental Toxicology and Chemistry, 28, 2473-2484.

Corlett, R. T., Primack, R. B., Devictor, V., Maas, B., Goswami, V. R., Bates, A. E., Koh, L. P., Regan, T. J., Loyola, R., Pakeman, R. J., Cumming, G. S., Pidgeon, A., Johns, D., Roth, R., 2020. Impacts of the coronavirus pandemic on biodiversity conservation. Biological Conservation, doi: 10.1016/j.biocon.2020.108571.

Cunningham, A. A., Dazak, P., Wood, J. L. N. 2017. One health, emerging infectious diseases and wildlife: Two decades of progress? Philosophical Transactions of the Royal Society B: Biological Sciences 372, 20160167.

Department of Health, 2020. The Philippine health system at a glance. https://www.doh.gov.ph/sites/default/files/basic-page/chapter-one.pdf, accessed April 14, 2020.

El-Halwagi, M. M., 2006. Process integration. Amsterdam: Elsevier.

Ferguson NM, Laydon D, Nedjati-Gilani G, Imai N, Ainslie K, Baguelin M, Bhatia S, Boonyasiri A, Cucunubá Z, Cuomo-Dannenburg G, Dighe A, Dorigatti I, Fu H, Gaythorpe K, Green W, Hamlet A, 
Hinsley W, Okell LC, van Elsland S, Thompson H, Verity R, Volz E, Wang H, Wang Y, Walker PGT, Walters C, Winskill P, Whittaker C, Donnelly CA, Riley S, Ghani AC. Impact of non-pharmaceutical interventions (NPIs) to reduce COVID-19 mortality and healthcare demand. COVID-19 Reports, Faculty of Medicine, Imperial College, London, UK 2020; doi:10.25561/77482.

Friedler, F., Aviso, K. B., Bertok, B., Foo, D. C. Y., Tan, R. R. 2019. Prospects and challenges for chemical process synthesis with P-graph. Current Opinion in Chemical Engineering, 26, 58-64.

Klemeš, J. J., Kravanja, Z., 2013. Forty years of Heat Integration: Pinch Analysis (PA) and Mathematical Programming (MP). Current Opinion in Chemical Engineering, 2, 461-474.

Klemeš, J. J., Varbanov, P. S., Walmsley, T. G., Jia, X., 2018, New directions in the implementation of Pinch Methodology (PM). Renewable and Sustainable Energy Reviews, 98, 439-468.

Klemeš, J. J., Fan, Y. V., Tan, R. R., Jiang, P., 2020. Minimising the present and future plastic waste, energy and environmental footprints related to COVID-19. Renewable and Sustainable Energy Reviews (in review).

Koyuncu, M., Erol, R., 2010. Optimal resource allocation model to mitigate the impact of pandemic influenza: A case study for Turkey. Journal of Medical Systems, 34, 61-70.

Kupferschmidt, K., Cohen, J. 2020. WHO launches global megatrial of the four most promising coronavirus treatments. Science, doi:10.1126/science.abb8497.

Liu, M., Xu, X., Cao, J., Zhang, D., 2019. Integrated planning for public health emergencies: A modified model for controlling H1N1 pandemic. Journal of the Operational Research Society, doi: 10.1080/01605682.2019.1582589.

Majumdar, A., Pal, A., 2020. Recent advancements in visible-light-assisted photocatalytic removal of aqueous pharmaceutical pollutants. Clean Technologies and Environmental Policy, 22, 11-42.

Medlock, J., Galvani, A. P., 2009. Optimizing influenza vaccine distribution. Science, 325, 1705-1708. 
Musazzi, U. M., Di Giorgio, D., Minghetti, P., 2020. New regulatory strategies to manage medicines shortages in Europe. International Journal of Pharmaceutics, 579, 119171.

Okuyama, Y., 2014. Disaster and economic structural change: Case study on the 1995 Kobe earthquake. Economic Systems Research, 26, 98-117.

Philippine Statistics Authority, 2020a. National Quickstat for 2020. https://psa.gov.ph/statistics/quickstat/national-quickstat/all/*, accessed on April 14, 2020.

Philippine Statistics Authority, 2020b. 2018 Quickstat of National Capital Region. https://psa.gov.ph/statistics/quickstat/regional-quickstat/2018/National\%20Capital\%20Region, accessed on April 14, 2020.

Santos, J. R., May, L., Haimar, A. E., 2013. Risk-based input-output analysis of influenza epidemic consequences on interdependent workforce sectors. Risk Analysis, 33, 1620-1635.

Sun, L., Depuy, G. W., Evans, G. W., 2014. Multi-objective optimization models for patient allocation during a pandemic influenza outbreak. Computers and Operations Research, 51, 350-359. doi: 10.1016/j.cor.2013.12.001

Tuite, A. R., Fisman, D. N., Kwong, J. C., Greer, A. L., 2010. Optimal pandemic influenza vaccine allocation strategies for the Canadian population. PLOS One, 5, e10520.

World Health Organization, WHO COVID-19 Dashboard, https://who.sprinklr.com/, accessed on April $12,2020$.

$\mathrm{Xu}, \mathrm{Y}$., 2020. Unveiling the origin and transmission of 2019-nCoV. Trends in Microbiology, 28, 239-240. Yaesoubi, R., Cohen, T., 2016. Identifying cost-effective dynamic policies to control epidemics. Statistics in Medicine, 35, 5189-5209.

Yu, D. E. C., Razon, L. F., Tan, R. R., 2020. Can global pharmaceutical supply chains scale up sustainably for the COVID-19 crisis? Resources, Conservation and Recycling (in press). 
Yu, K. D. S., Aviso, K. B., 2020. Modelling the economic impact and ripple effects of disease outbreaks. Process Integration and Optimization for Sustainability, doi:10.1007/s41660-020-00113-y.

Yuan, J., Lu, Y., Cao, X., Cui, H., 2020. Regulating wildlife conservation and food safety to prevent human exposure to novel virus. Ecosystem Health and Sustainability, 6, 1741325.

Zhang, T., Wu, Q., Zhang, Z., 2020. Probable pangolin origin of SARS-CoV-2 associated with the COVID-19 outbreak. Current Biology, 10.1016/j.cub.2020.03.022.

Zhou, P., Yang, X.-L., Wang, X.-G., Hu, B., Zhang, L., Zhang, W., Si, H.-R., Zhu, Y., Li, B., Huang, C.L., Chen, H.-D., Chen, J., Luo, Y., Guo, H., Jiang, R.-D., Liu, M.-Q., Chen, Y., Shen, X.-R., Wang, X., Zheng, X.-S., Zhao, K., Chen, Q.-J., Deng, F., Liu, L.-L., Yan, B., Zhan, F.-X., Wang, Y.-Y., Xiao, G.-F., Shi, Z.-L., 2020. A pneumonia outbreak associated with a new coronavirus of probable bat origin. Nature, $579,270-273$. 
Figures

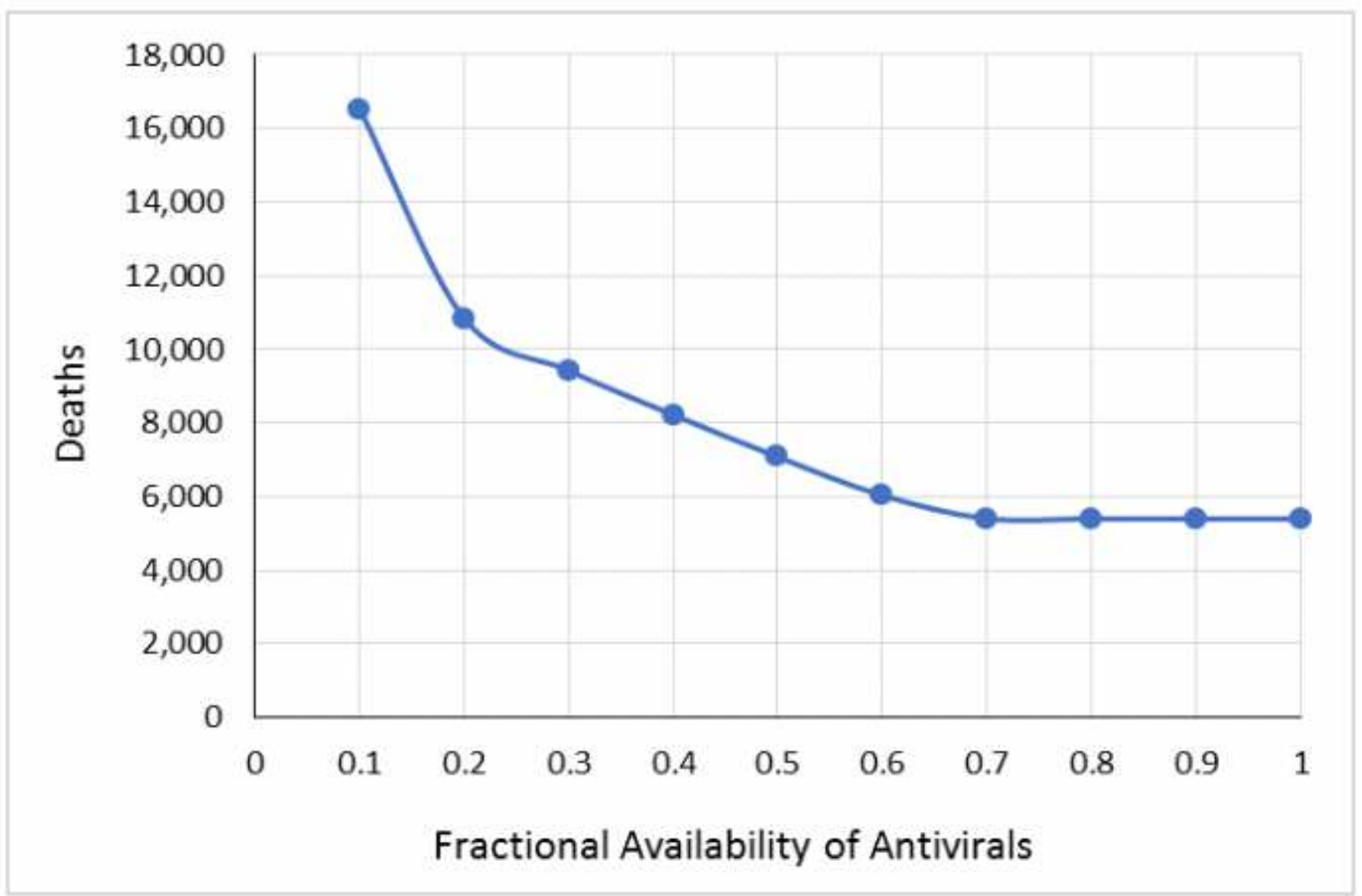

Figure 1

Variation in number of deaths relative to availability of antivirals 


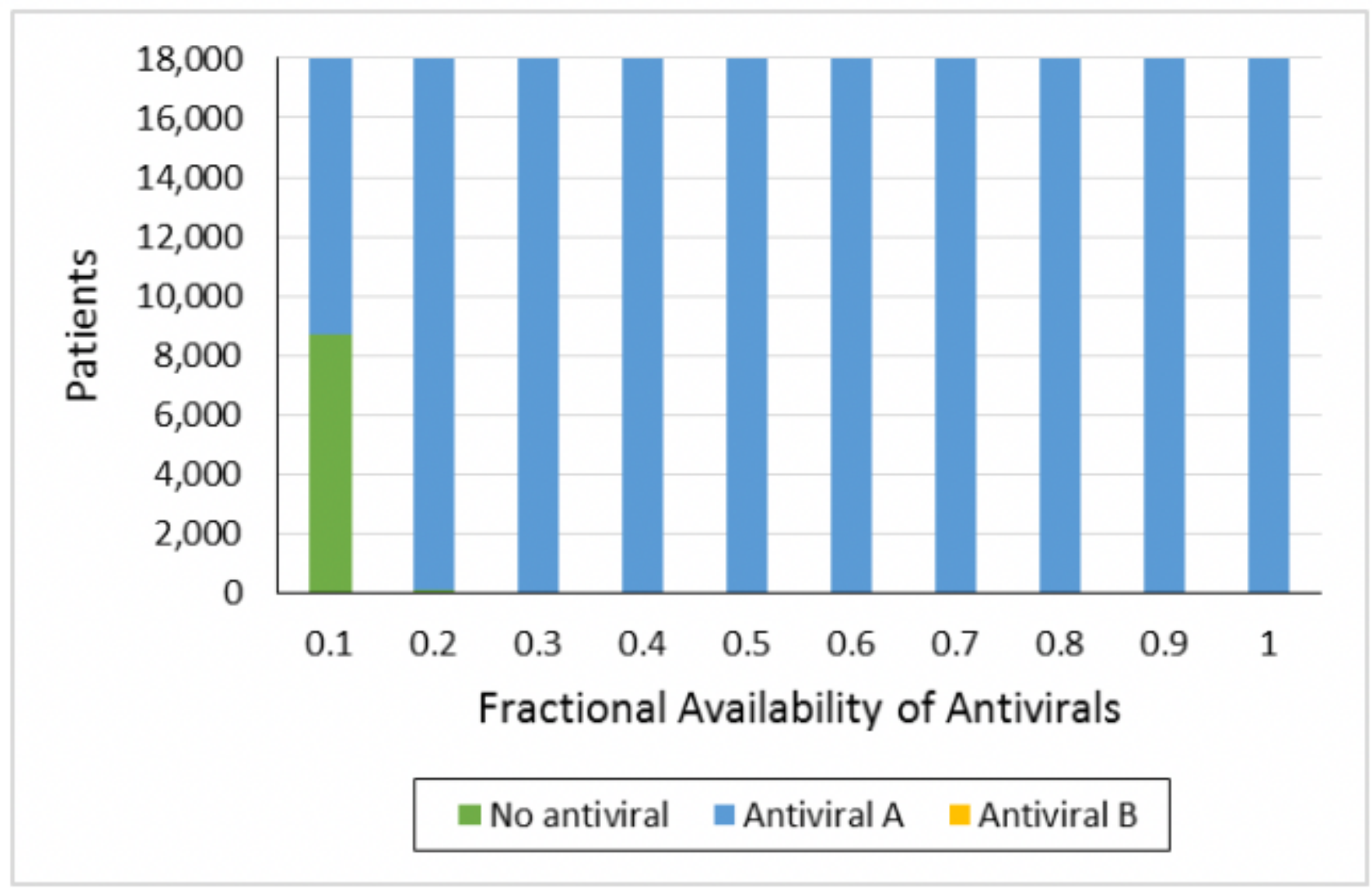

Figure 2

Allocation of antivirals to critical case patients. 


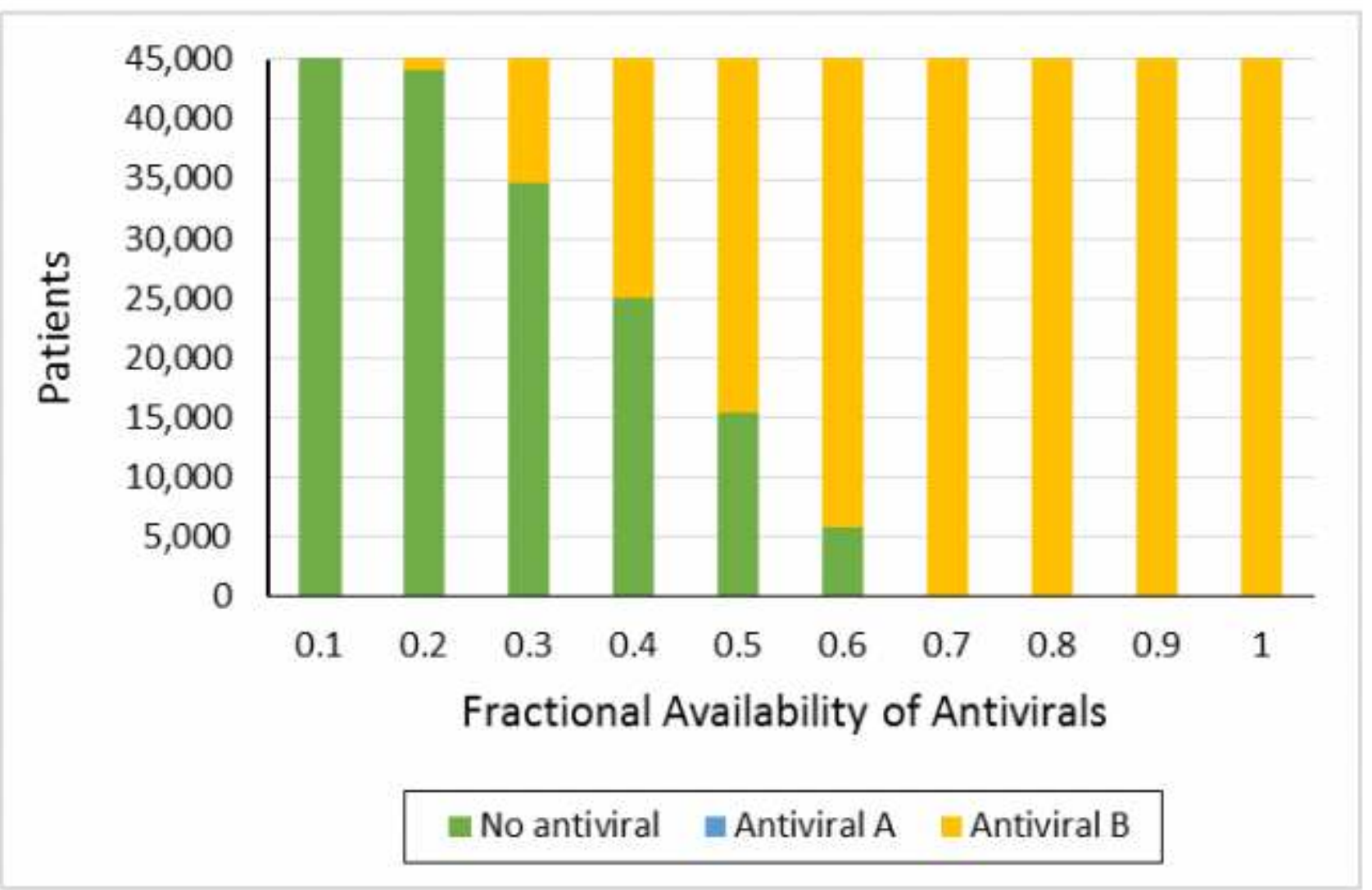

Figure 3

Allocation of antivirals to moderate case patients 


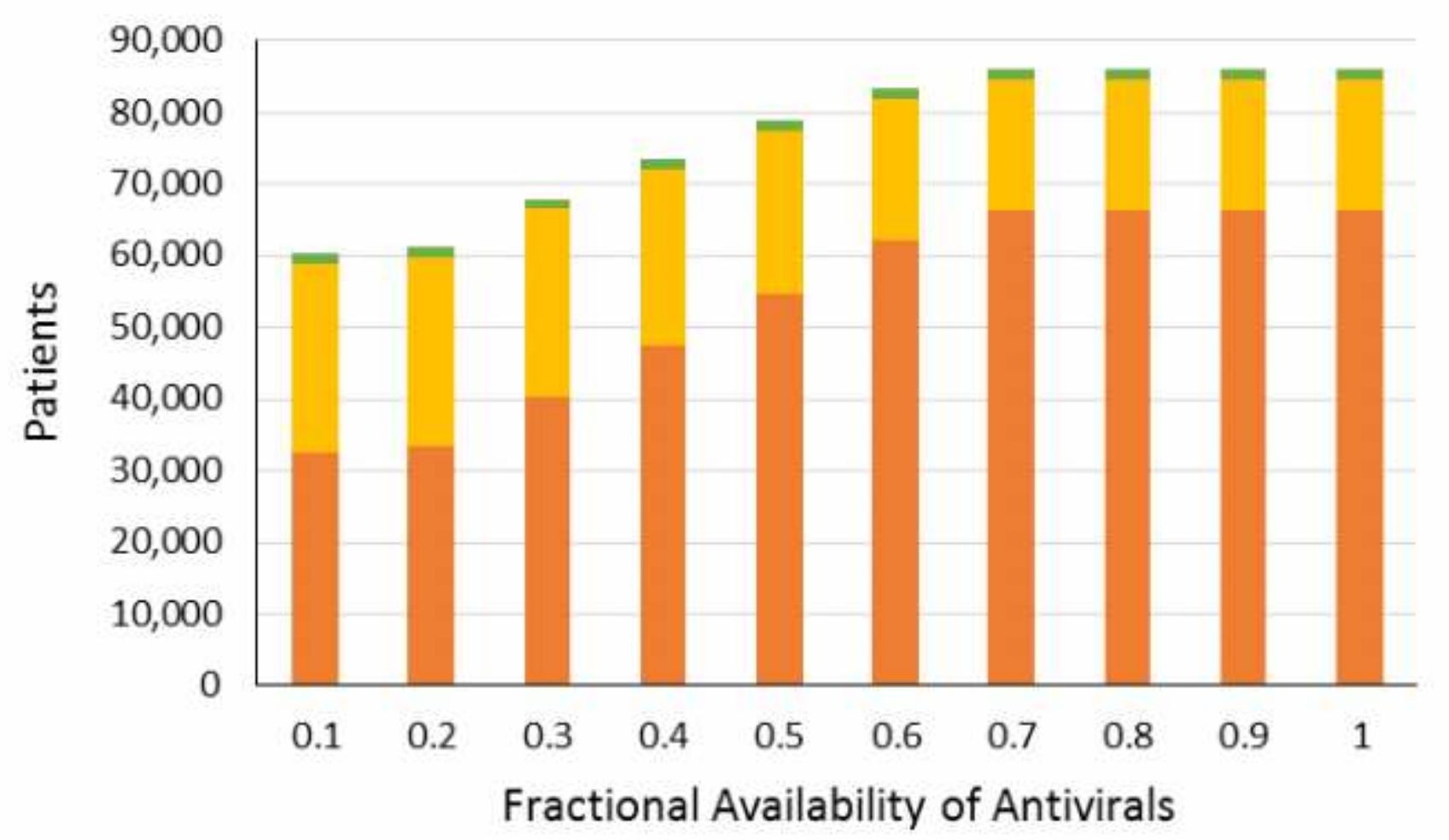

Home $=$ Bed $=\mathrm{ICU}$

Figure 4

Distribution of patients at different levels of antiviral availability 


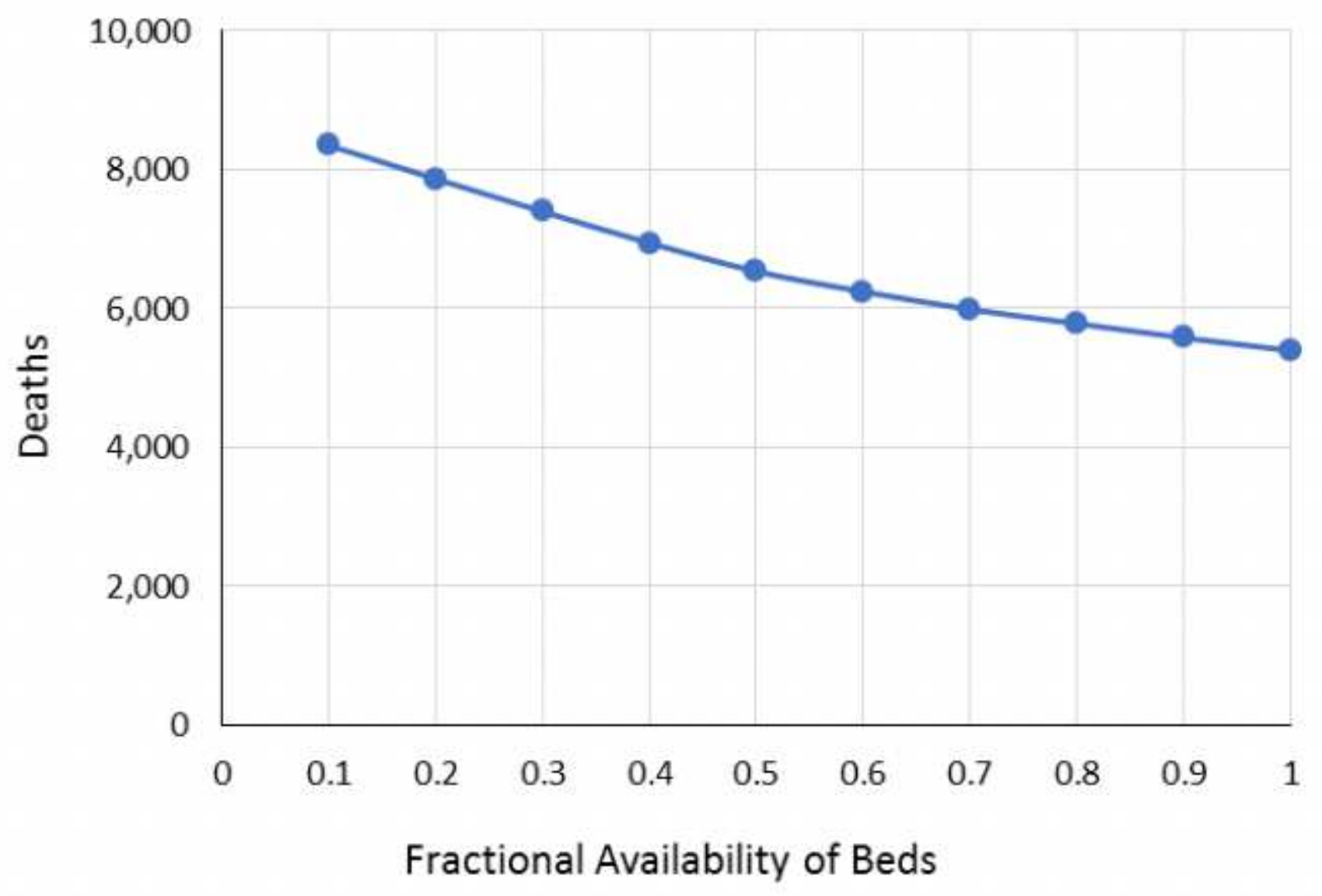

Figure 5

Variation in number of deaths relative to availability of hospital resources 


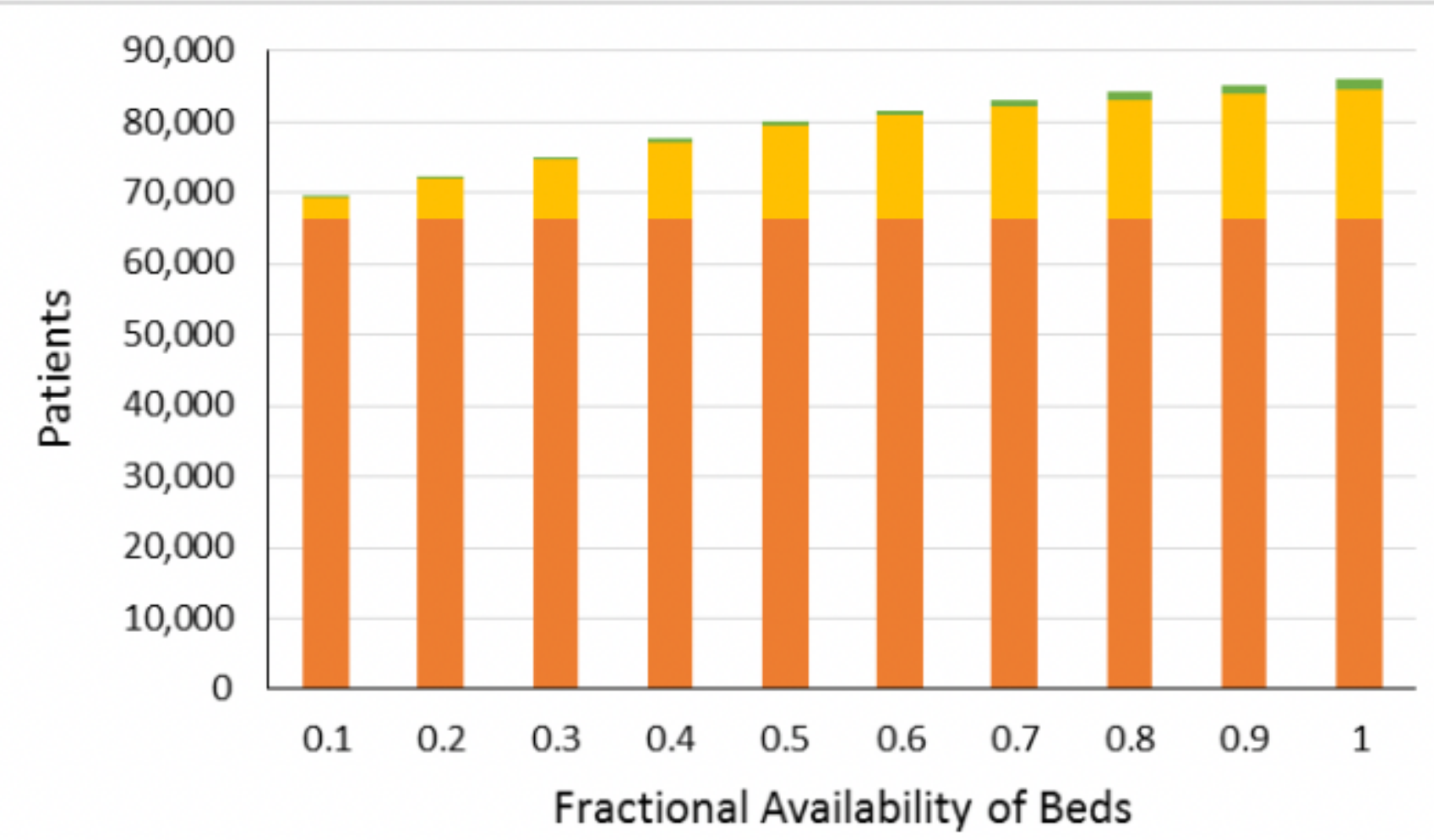

Home Bed $\square$ ICU

Figure 6

Distribution of patients at different levels of hospital resource availability 